\title{
New head of NEC research institute in US hopes to change our view of computers
}

Princeton, New Jersey. A determined effort by a Japanese company to create a worldclass US laboratory for basic research on computers took an important step forward last week with the appointment of C. William Gear as director of the NEC Research Institute.

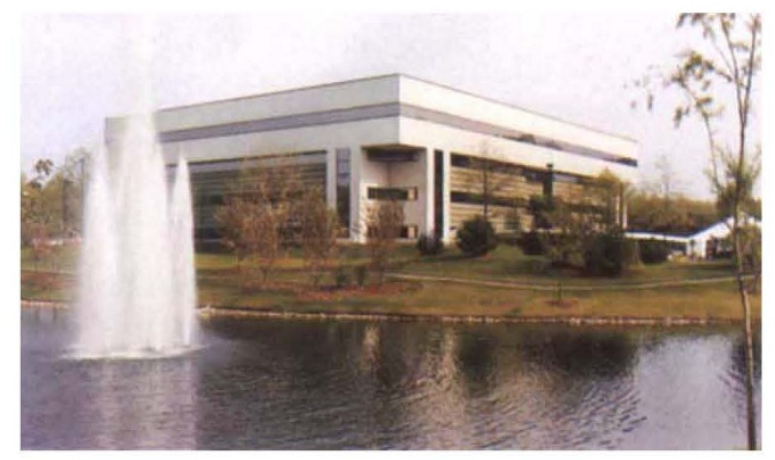

NEC's Princeton institute is healthy toddler.

The NEC Corporation announced on 2 November that Gear, a 57-year-old computer scientist, would lead its youngest research laboratory, formed in 1989 in Princeton. Gear joined the institute as a vice president in its first year after spending more than 25 years with the computer science department at the University of Illinois at Urbana-Champaign. With his predecessor, the late Dawon Kahng, Gear laid the foundation for a laboratory expected to generate revolutionary ideas by the end of the century about how people build, think about and use computers.

Gear says that the NEC project contains an element of enlightened self-interest along with a streak of altruism. "Just because we don't have to worry about applications now doesn't mean that we can ignore the [parent] company altogether", he says.

Even so, the differences between Gear's task and that of many other research directors can be measured in dollars and deadlines. The past year has been a tough one for research. Spending by US corporations is flat, with annual average growth slowing from 7.5 per cent between 1980 and 1985 to a mere 0.4 per cent between 1985 and 1991 , according to the National Science Foundation. Japanese companies are similarly cutting back on research as their profits tumble (see Nature 356, 93; 1992).

But the NEC Research Institute, which officially opened its doors in May 1989, has so far been spared such cuts. Although the pace of hiring has slowed, the current staff of about 40 is still expected to grow by a third within five years. "[Hiring] nine new people a year was too fast," he says about the original plan to reach full capacity in three years. "Five [a year] is plenty fast enough."

NEC has been generous with its US offspring, providing it with more than $\$ 25$ million last year. Although that may be only a tenth of a percentage point of its gross revenue, it is still a significant amount to spend when most companies are retrenching. And while it is dwarfed by the half-billion dollars that IBM spends annually on basic research, it is almost a quarter of what Xerox spent last year and not a bad showing for a corporate toddler.

At the same time, the cost is minuscule alongside the company's more traditional applied research and development programmes. In Japan, NEC has about a dozen such groups, which last year consumed some 12 per cent, or approximately US $\$ 3$ billion, of NEC's sales.

But that money comes with strings attached. For instance, while ideas may percolate from the research staff up to management, managers evaluate those proposals within a framework of well-defined corporate needs. Ideas that do not fit into the prescribed goals are ignored.

What is more, as NEC's profits have skittered downhill during the past year, the budgets of the applied research laboratories in Japan have suffered. Stay small, one Japanese research director advised his Princeton colleagues, and you may avoid the pain of future cutbacks.

Gear believes that stable funding is essential because scientists can become too cautious if money becomes a primary concern. He uses the carrot of steady funding to coax researchers to apply insights from one field to the unsolved problems of another.

Towards that end, the laboratory's budget is divided among individual researchers, not projects. Theorists and experimentalists are ranked according to seniority and are awarded corresponding budgets to spend as they see fit without having to provide elaborate justifications. For instance, a senior theorist may receive $\$ 50,000$ a year in addition to his or her salary, and an experimentalist more. A governing board of five to eight institute fellows approves additional expenditures for equipment.

So far, researchers at the institute have few complaints. "We've been allowed to follow our noses", says senior research scientist Eric B. Baum. Their work is spread across the spectrum of computing and physi- cal sciences, with several scientists exploring how machines and people learn. For example, Baum is studying games such as chess and go to explain consciousness and find an alternative to the classic approach of designing a tree with branching options, which he says does not capture the way in which a go player plots strategy.

Elsewhere at the institute, scientists study the brain by asking a simple question: how does a fly keep to a straight course? They hope that the answer will help to explain the way people process external stimuli. Other researchers are exploring such problems as connecting very large numbers of processors with optical links and using computing linguistics to add more natural language interfaces into such systems.

NEC's Princeton institute is not the only US laboratory of its kind run by a

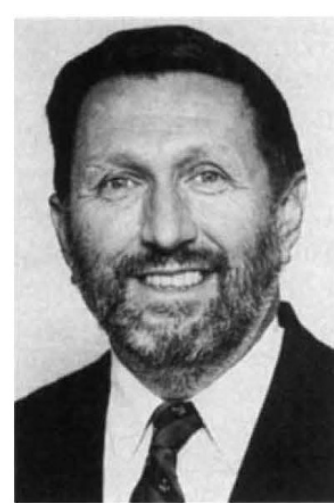

c. William Gear Japanese corporation. Last year, Laszlo A. Belady, formerly a vice president at the Microelectronics and Computer Technology Corporation (MCC), began assembling a basic-research laboratory in Cambridge, Massachusetts, for Mitsubishi

Electric. "I was practically given a free ticket," he says. His goal is to explore ways in which information technology can improve "multicultural and multinational" collaboration as well as to provide learning experiences in the work place.

Unlike Gear, Belady expects his laboratory to devote at least a third of its time to applied problems. "When they say, 'Don't worry about applications,' I say, 'Yes, sir!' but I don't believe them", says Belady. "It's not necessarily the top executives who will change their minds, but the middle management will eventually be unhappy and kill you."

Although it is not clear whether the NEC institute can maintain its emphasis on the long term if corporate profits continue to shrink, Gear says that his bosses have not changed their tune. "I'm not concerned about identifying some product" that owes its existence to work done at his laboratory, he says. However, he hopes that within five years his researchers will have changed the way NEC scientists in Japan think about the future of computing and communications.

Elizabeth Corcoran 